Arteterapia. Papeles de arteterapia y educación para inclusión social ISSN-e 1988-8309

http://dx.doi.org/10.5209/ARTE.58888

\title{
Procesos creativos e imágenes como herramientas etnográficas en el estudio del envejecimiento
}

\author{
Denisse Zamorano Enríquez ${ }^{1}$
}

Recibido: 15 de febrero de 2018 / Aceptado: 3 de julio de 2018

Resumen. El artículo aborda el alcance de una metodología a través de la imagen y los procesos creativos del arte dentro del contexto de una investigación antropológica en colaboración con el arteterapia sobre los procesos de envejecimiento en un grupo de mujeres de la ciudad de Quito-Ecuador. Incluye un breve estado de la cuestión y una muestra del proceso, en donde se ubica a la imagen, el cuerpo y el relato de vida como puntos de encuentro entre disciplinas. Concluye destacando el potencial del arte en la metodología y producción de conocimiento social, en tanto promueve acercamientos dialógicos y reflexivos entre agentes sociales e investigadores; facilita la activación de memorias; ofrece otras formas de articulación narrativa; entre otros.

Palabras clave: imagen; arte; etnografía; procesos de envejecimiento; mujeres mayores.

\section{[en] Creative processes and images as ethnographic tools in the aging study}

Abstract. The article addresses the scope of a methodology through the image and creative processes of art within the context of anthropological research in collaboration with art therapy on the aging processes in a group of women from the city of Quito-Ecuador. It includes a brief state of the question and a sample of the process, from where the image, the body and the story of life are located as points of encounter between disciplines. Concludes by highlighting the potential of art in the methodology and production of social knowledge, as it promotes dialogical and reflexive approaches between social agents and researchers; facilitates the activation of memories; offers other forms of narrative articulation; among others.

Keywords: image; art; ethnography; aging processes; older women.

Sumario. 1. Arteterapia y Antropología Visual. 2. Metodología. 3. El grupo de mujeres participantes. 4. Lenguajes del arte y principales temáticas emergentes. 4.1. El dibujo y la manifestación de casa como espacio vital. 4.2. La arcilla y su potencial para evocar el tema de la muerte. 4.3. La importancia de las relaciones afectivas y sociales durante esta etapa de la vida: ejemplos a partir del collage. 5. Imagen, relato de vida y cuerpo: destacados puntos de encuentro entre Arteterapia y Antropología Visual. 6. Conclusiones. 7. Bibliografía.

Cómo citar: Zamorano Enríquez, D. (2018). Procesos creativos e imágenes como herramientas etnográficas en el estudio del envejecimiento, en Arteterapia. Papeles de arteterapia y educación para inclusión social 13, 2018, 33-52.

1 Escultora y arteterapeuta de la Universidad de Chile, y antropóloga visual de la Facultad Latinoamericana de Ciencias Sociales (FLACSO). Departamento de Antropología Historia y Humanidades, con sede en Ecuador. FLACSO-Ecuador.

E-mail: delaluzdelsol2.0@gmail.com 


\section{Arteterapia y Antropología Visual}

El siguiente artículo deriva de un trabajo de tesis que surge de la idea de que el arteterapia y la antropología visual pueden conformar un buen equipo de investigación. En este caso para explorar las experiencias del envejecimiento en un grupo de mujeres de entre 52 a 88 años de edad, pobladoras de un barrio clase media-popular de la ciudad de Quito. No obstante, esta idea colaborativa no es inédita, dentro de las referencias es posible hallar trabajos como los de Susan Hogan \& Sarah Pink (2010), Marxen (2009, 2011), Espinoza, Osorio \& Reyes (2016) quienes desde ambas disciplinas proponen al arte y los procesos creativos del arte no sólo como herramientas terapéuticas sino también etnográficas.

Entre los beneficios de esta relación interdisciplinar Hogan \& Pink (2010) en su ensayo titulado «Routes to Interiorities: Art Therapy and Knowing in Anthropology» destacan - entre otras cosas-, la movilización de nuevas formas expresivas y de representación en la antropología, así como también el acceso a los estados mentales y anímicos de los sujetos, los cuales muchas veces no están disponibles como información consciente o son difíciles de articular por medio del lenguaje verbal.

Por su parte, Eva Marxen, quien comparte la formación de ambas disciplinas, concibe el arte no sólo como un instrumento social con poder político y terapéutico (2011) sino como una herramienta etnográfica de gran alcance, en tanto posibilita «la ampliación, la ilustración, y la contrastación de las narrativas de los y las informantes» (2009, p. 9) permitiéndoles al mismo tiempo posicionarse en un rol activo y creativo dentro del proceso de investigación.

En esta línea, está también el trabajo de Espinosa, Osorio y Reyes (2016) — quienes a propósito del terremoto y posterior tsunami ocurrido en las costas de Chile en el año 2010 - proponen una intervención interdisciplinaria entre arteterapia y antropología con los adultos mayores de las zonas más afectadas por la catástrofe. Se trata de una metodología mediada por la música y el arte que busca recabar información sobre los estados emocionales de este colectivo. Entre los beneficios de esta intervención las autoras señalan no sólo los efectos terapéuticos experimentados por los adultos mayores a través de la participación creativa sino también la identificación de varias de las fortalezas de este colectivo frente a la adversidad.

Por otro lado, desde la antropología y la antropología visual, investigadores como Irving (2007, 2009), Taussing (2009), Ferraz (2013), Riaño (2005), Lammer (2013) entre otros, desde diversos escenarios y enfoques integran así mismo una diversidad de lenguajes del arte - dentro de la comunicación con los informantes-, como el dibujo, la pintura, la fotografía, la instalación, la música, las artes escénicas, etc., coincidiendo con la idea y la evidencia de que el arte y los procesos creativos del arte facilitan el acceso a la interioridad de los sujetos, promueven la articulación de otras formas narrativas y comunicativas más allá del nivel puramente verbal, permiten incorporar el cuerpo y los afectos en la investigación social, entre otros.

De igual modo, - en sintonía con el enfoque de este trabajo-, Ardèvol (2009) plantea la integración de otras formas perceptivas en la antropología como el tacto, el oído, el olfato, etc., enfatizando la importancia del cuerpo y la experiencia en la construcción teórica y como parte fundamental de los procesos sociales y culturales que se analizan. Esta integración sensorial apuntaría según Ardèvol, no sólo a lograr una experiencia empática con los sujetos en el trabajo de campo, sino también a tomar en cuenta las emociones y percepciones tanto de los investigadores 
como de los informantes, de tal forma que puedan ser procesadas e incorporadas en la producción teórica.

En este sentido, cabe señalar que si bien la imagen y el arte en la investigación antropológica toman fuerza hace un poco más de una década, han estado presentes desde el inicio de la disciplina, pues ya en tiempos de Malinowski ${ }^{2}$ la fotografía es utilizada como una reivindicación de la presencia del antropólogo en el campo. Se trata, en esta primera instancia de una herramienta al servicio de una ciencia positivista apoyada en la idea de que este dispositivo es capaz de registrar objetivamente la realidad.

Paulatinamente otros antropólogos como Boas, Mead, Bateson, Curtis, Rouch, etc., descubrirán y aprovecharán desde diversos enfoques y metodologías el potencial visual y audiovisual del cine y el video en la investigación social y cultural hasta llegar a una antropología contemporánea interesada en la vida interior de las personas y en la integración de una vasta gama de lenguajes artísticos como herramientas etnográficas. Integración que es ampliamente promovida en trabajos como «Contemporary art and anthropology» (2006) en donde Schneider \& Wright hacen un llamado a la renovación creativa de la disciplina a través de la incorporación de imágenes y las diversas formas del arte, pero no como objetos de estudio, sino desde el aprovechamiento de su potencial afectivo, sensorial y tridimensional.

Para esto, Schneider \& Wright (2006) parten de una desmitificación de las categorías reificadas por la academia tanto del arte como de la antropología, desde donde promueven el diálogo creativo entre disciplinas. Se trata según ellos de híbridos colaborativos capaces de desestabilizar las fronteras disciplinares hacia la utilización de nuevas categorías de análisis para abordar las prácticas sociales, culturales o estéticas.

\section{Metodología}

De acuerdo a los objetivos de la investigación — centrados en la exploración y visibilización de los procesos de envejecimiento a partir de un modelo teórico- metodológico compartido entre el arteterapia y la antropología visual-, el trabajo de campo etnográfico se desarrolló durante 24 semanas. 12 de ellas integraron algunas herramientas de la antropología, como observación participante, entrevistas en profundidad, y un ejercicio inicial de video elicitación con el grupo completo de la «tercera edad $\iota^{3}$. Y 12 semanas incorporaron una metodología a través de la imagen y los procesos creativos del arte, llevados a cabo en el espacio en la Casa Barrial ${ }^{4}$, dentro de un contexto que tomó varios elementos del setting arteterapéutico.

En este sentido, la imagen y los procesos de creación artística han sido planteados principalmente como motivadores y mediadores de relatos de vida y auto expresiones en torno a los procesos de envejecimiento antes que como recursos de exploración y elaboración de conflictos personales. Esto, más allá de los efectos terapéuticos que pudieron derivar del trabajo con el arte en sí mismo, el proceso y/o la relación entre la investigadora y las agentes sociales.

\footnotetext{
Uno de los pineros de la antropología social y la metodología del trabajo de campo.

Denominado y conformado así por el Centro de Salud del Sector, incluye aproximadamente 16 mujeres mayores. Espacio utilizado por la comunidad barrial para llevar a cabo diferentes actividades como reuniones informativas, cursos, talleres, fiestas, entre otras.
} 
En cuanto al abordaje grupal, este fue pensado como una forma de ampliar la discusión y la reflexión sobre las diversas experiencias del ir envejeciendo. Así mismo, cabe mencionar que durante el proceso de invitación y conformación del grupo, las participantes fueron informadas sobre los objetivos de la investigación, los tiempos y protocolos de participación, y fueron consultadas para ser fotografiadas y grabadas con video cámara.

En base al tiempo y la propuesta general, el taller a través del arte se organizó los días viernes de 3 a 5: 30 de la tarde, bajo la modalidad directiva y semidirectiva, e integró diversos ejercicios, técnicas y materiales. Como sabemos desde el arteterapia todas las artes pueden ser utilizadas como vías de conocimiento (Klein, 2006, López, \& Martínez, 2006; etc.). En este caso me remití principalmente al uso de las artes visuales como el dibujo, la pintura, el collage, o la arcilla. No obstante, en algunos momentos recurrí a la imaginación, al uso de objetos e imágenes preexistentes, a la estimulación sensorial con olores y al movimiento corporal. Pese a esta modalidad directiva, el acercamiento estuvo continuamente disponible al cambio y a las necesidades del momento.

\section{El grupo de mujeres participantes}

El grupo, conformado por nueve mujeres de entre 52 a 88 años de edad, todas pobladoras de un barrio clase media popular de la ciudad de Quito, participó de forma voluntaria en la investigación. En la mayoría de los casos, motivadas por la socialización y la adquisición de nuevos conocimientos y experiencias en torno al arte y a sus procesos personales.

Durante los primeros encuentros y acercamientos de observación al grupo, me informé - entre otras cosas_-, que algunas de ellas son amas de casa que viven con sus familias y otras viven solas. En varios casos debido a la falta de jubilación, pensiones u otra clase de ingresos económicos deben trabajar en diferentes actividades y/o dependen de sus hijos. Por otro lado, todas - aunque en diferente nivel de complejidad - , manifiestan tener algún problema de salud, los cuales son atendidos en su totalidad dentro del sistema de la salud pública.

Así mismo, durante las entrevistas personales previas al trabajo con arte pude acceder a algunos datos biográficos, entre ellos destacan que todas son originarias del campo que han debido migrar a la ciudad en busca de mejores oportunidades económicas. Con excepción de una participante todas tienen problemas con la lectura y la escritura pues sólo hace un par de años atrás han podido ser alfabetizadas. En varios casos han sido madres solteras y muchas de ellas han sido víctimas de violencia en diferentes niveles por parte de sus cónyuges y otros hombres.

Se trata de un grupo consolidado no sólo por vínculos de vecindad, una gran participación social dentro de la comunidad a través de distintos talleres y programas públicos y privados destinados a «la tercera edad», sino que entre algunas de ellas existen además lazos de parentesco.

\section{Lenguajes del arte y principales temáticas emergentes}

\subsection{El dibujo y la manifestación de casa como espacio vital}

Durante el trabajo de campo el dibujo fue uno de los lenguajes más utilizados, ya sea como propuesta mía o elección de las participantes, pues aunque en general el grupo 
manifiesta tener poca o nula experiencia con el arte, el dibujo es uno de los lenguajes que han podido experimentar, ya que cuando asistieron a los programas públicos de alfabetización el profesor les proponía recurrentemente esta actividad.

A partir del dibujo me fue posible apreciar no solo algunas de las principales preocupaciones y/o motivaciones afectivas y emocionales del grupo, vinculadas especialmente al tema de la vivienda, la soledad o la importancia asignada a las relaciones sociales durante esta etapa de la vida, sino también algunas complicaciones físicas como el caso de Blanca - participante de 84 años-, quien por su artrosis y cataratas en ambos ojos presenta limitaciones motrices y visuales que le impiden sujetar y ver las líneas de los lápices de palo, por lo que prefiere dibujar con los pasteles grasos.

Por otro lado, durante la producción visual y a partir de algunos ejercicios o pies forzados, el tema del hogar o la casa como espacio vital es uno de los más sobresalientes. Así, en nuestro segundo encuentro, al pedirles que imaginen ser unas directoras de cine a punto de realizar las películas de sus vidas, y dibujen la cartelera de dicha película, todas sin previo acuerdo entre ellas hacen un viaje a la casa de la infancia en el campo.

Sobre la casa, Aramburu \& Tapada (2011) señalan que se trata de uno de los espacios más importantes para la reproducción de las sociedades, que permite dar cuenta no sólo de la idiosincrasia particular y doméstica de las personas sino de las condiciones sociales, políticas, culturales, etc. en las que se insertan. Así mismo sostienen que su uso y las prácticas que en ella se desarrollan aportan importante información en cuanto al «reparto del poder, la pertenencia de clase, la apropiación y acceso a recursos y derechos, así como las manifestaciones de las identidades sociales y las expresiones de la diversidad cultural» (Aramburu, \& Tapada, 2011, p.1).

En otras ocasiones durante el proceso, tanto el dibujo como la construcción de la casa se presentan como el logro de una vida de mucho esfuerzo y sacrificio como es el caso de María Isabel - participante de 52 años-, quien en la sesión número cuatro dibuja y posteriormente pinta su casa. Al preguntarle por esto, ella dice: «Mi casita no es de loza pero le quiero y me siento orgullosa de ella, de todo el esfuerzo que ha significado construirla» (Ver figura 1).

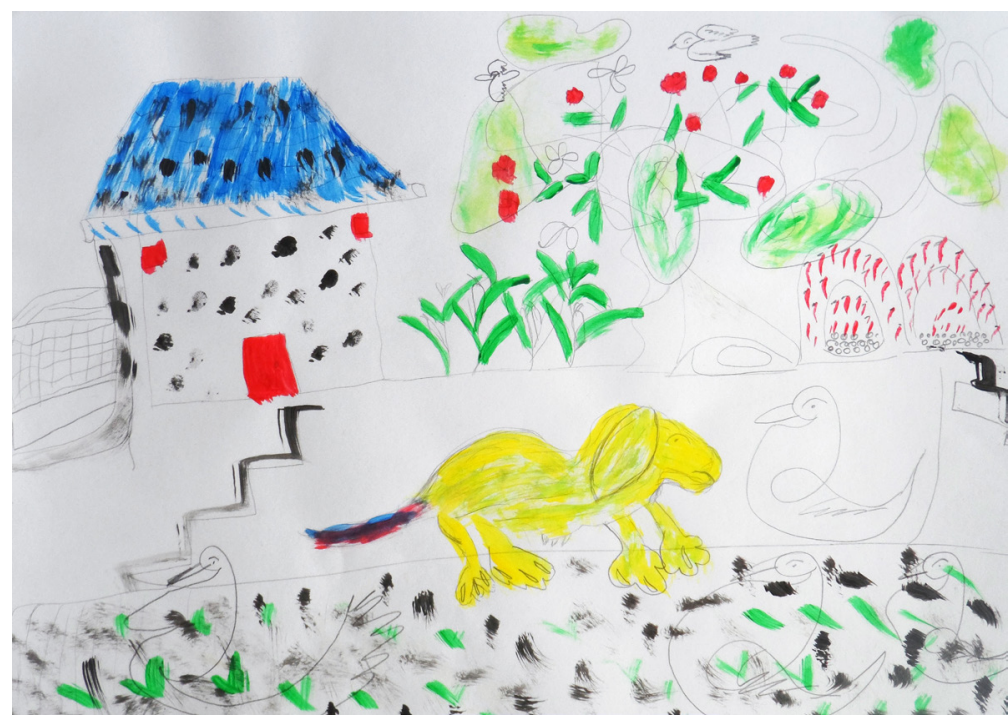

Figura 1 
En el caso de Hilda participante de 69 años de edad, la representación de la casa aparece en varios momentos como expresión de su actual angustia y ansiedad por no contar con un espacio propio, sumado a unas duras condiciones económicas que le obligan a seguir trabajando pese a sus dolencias y limitaciones físicas. En dos sesiones Hilda dibuja una casa y en otra la modela con arcilla. A una de ellas Hilda la titula: «Casita de pobres», al preguntarle por esto, ella responde así:

Porque yo soy pobre y no hay quien me ayude en nada y siempre he vivido en una chocita, primero en Guaranda, en mi tierra. Cuando vivía allá mi casa era una chocita tapada con xixe y era bien abrigadita, no entraba el agua, no entraba nada porque era tupida la paja (...) (Ver figura 2).

Así mismo en sus dibujos y verbalizaciones se repite la idea del sol, como una forma según ella de abrigarse, y la cama como símbolo de descanso, lo que no resulta extraño considerando que a su edad aún debe trabajar para su subsistencia.

El dibujo en este caso constituye un aliado comunicativo capaz de trascender la expresión verbal. Se trata como dice López (2006) de una actividad compleja en donde es fundamental considerar lo que dice la persona mientras dibuja, sus reacciones corporales en el momento, su contexto emocional, cultural, social, etc. antes que de un objeto para ser descifrado. Desde la antropología Taussig (2009) concibe el dibujo como una forma encarnada de comprender la realidad a partir de la experiencia del aquí y ahora pero también desde el lazo mimético que guarda con ella.

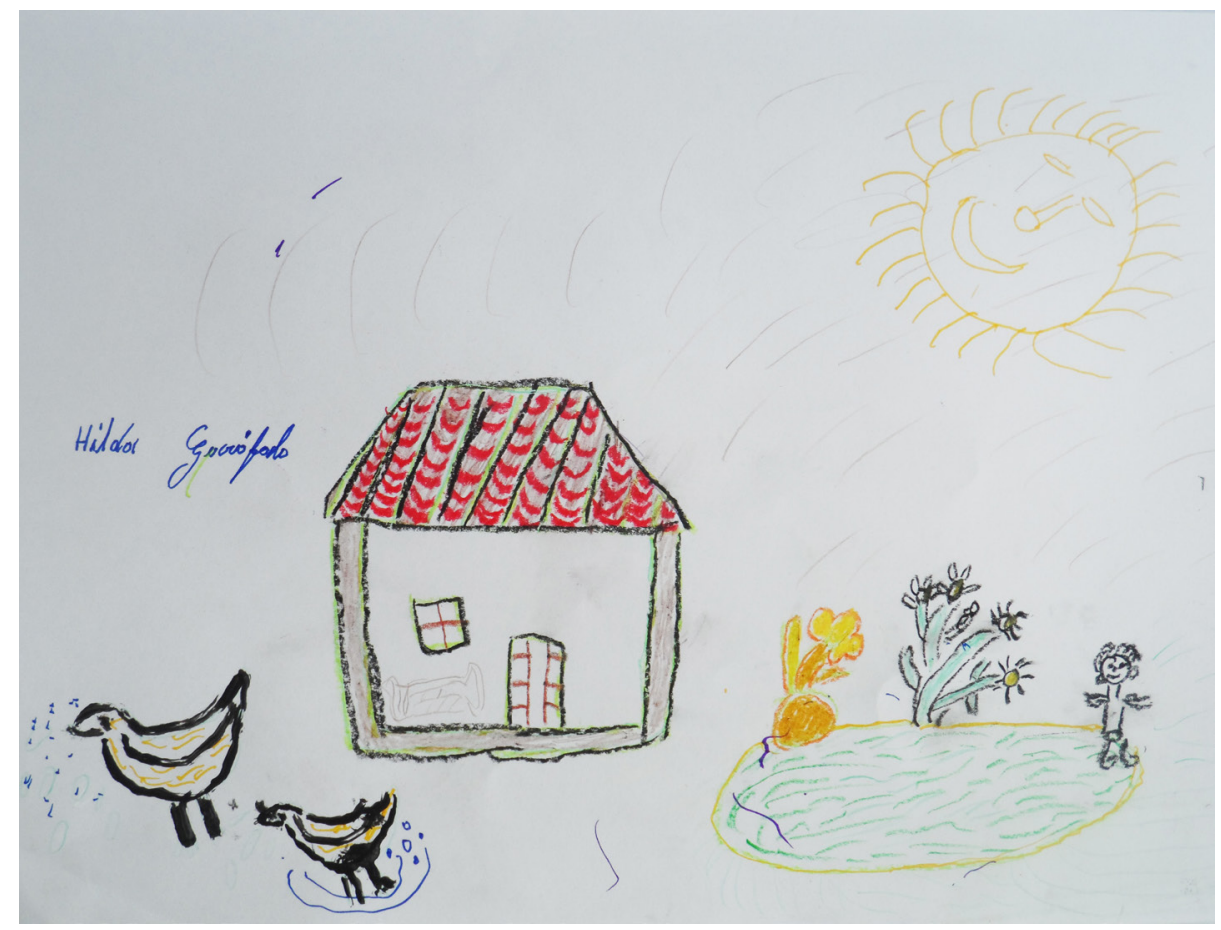

Figura 2 


\subsection{La arcilla y su potencial para evocar el tema de la muerte en este grupo}

La arcilla es uno de los materiales más potentes en arteterapia, pues implica no sólo movilización de energía sino transformación. Como dice Jarreau (1995) es el símbolo del origen y el fin de la vida, de ahí la frase bíblica «del polvo venimos y al polvo vamos». De acuerdo a varios arteterapeutas (Martínez, \& López 2006; Paín, \& Jarreau, 1995; Lusebrink, 2004, etc.) la arcilla es un medio que estimula experiencias sensoriales primarias y permite la emergencia de material inconsciente o reprimido, en este sentido considero que es mejor proponerla en la fase intermedia o final de los procesos

En el trabajo de campo, la creación con ella durante dos sesiones hace emerger por un lado el tema del abuso sexual en el contexto rural (tema que por su extensión y complejidad no puedo abordarlo aquí), pero también surge el tema de la muerte y los muertos. Aunque este tema ya aparece antes de forma tangencial durante un ejercicio con auto cajas, con la arcilla la muerte será abordada explícitamente.

Así, en la sesión número nueve, Teresa — participante de 88 años-, ha hecho nuevamente un viaje al pasado de su infancia en el campo, trayendo al presente el recuerdo de un hombre a quien un día encontró muerto en la entrada del túnel por el que ella tenía que transitar diariamente con su mula. Sobre su imagen Teresa dice:

Yo hice una figura incaica. Hice un cadáver (todas se ríen). Antes a los incaicos les enterraban parados. Entonces cavaban una fosa y ahí les acomodaban. A un lado el cántaro de chicha y al otro lado podía ser cuyes con papas. Entonces mientras caminaban iban sirviéndose la comida y la chicha. Hasta que yo creo que se terminaban de morir... (Después añade mientras mira su figura) entonces, digamos que hemos encontrado este cadáver y lo hemos llevado a la sepultura. No está amortajado sino que se va así. (Ver figura 3).

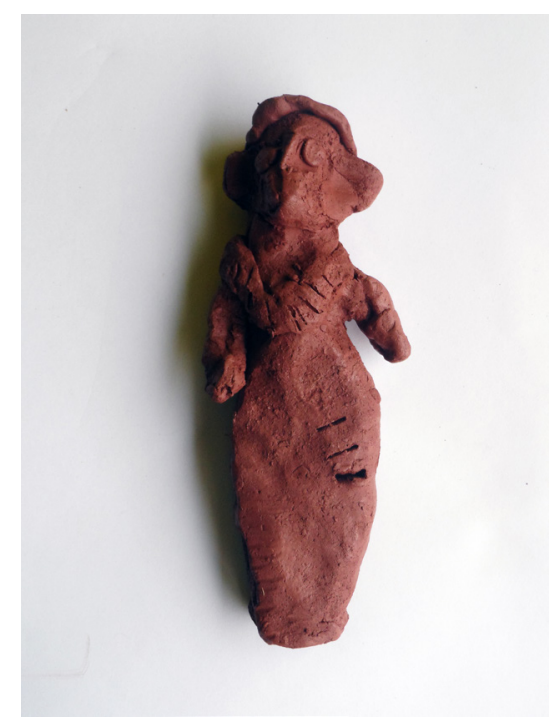

Figura 3 
Su preocupación en el presente sobre este personaje es poder darle según ella «una santa sepultura». El tema genera interés y algunas comentan su perspectiva personal sobre la muerte. Tránsito — participante de 74 años-, dice: «A mí una mujercita de mi tierra, me dijo que la muerte es bien bonita, no se le teme a la muerte». Teresa añade «yo no le temo a la muerte, porque no le debo nada a nadie». Mientras que Luz — participante de 60 años_-, dice:

A mí me dijo mi suegrita — que en paz descanse—, que iba a bajar para contarme como era la muerte. Y yo ya le he soñado como dos veces. Una vez me dijo: ¡Luz por favor que no me entierren con el sinvergüenza de mi marido! (todas se ríen).

Así mismo en la siguiente sesión con arcilla, Blanca crea una figura a la que titula «María Rudesinda», al preguntarle por ella, Blanca señala que se trata de su madre adoptiva, a quien hace como símbolo de protección y dice: «Ella es la persona que me crió (...) le hice porque quiero recordarle» (Blanca contempla con afecto su figura, mientras habla). «Me gustaría que esté viva, me gustaría estar al lado de ella» (Ver figura 4)

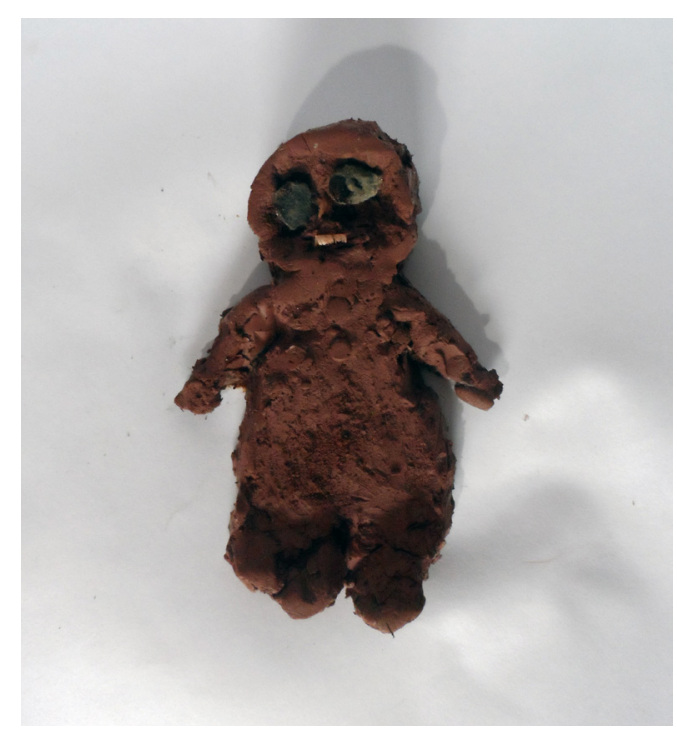

Figura 4

Louis-Vicent (1991) sobre la muerte en la sociedad occidental actual señala que es normal que se la rechace o trate como un tabú. Según él, se trata de un miedo no exento de culpa, que se manifiesta como una tendencia progresiva hacia la desritualización y desimbolización de las conductas funerarias. No obstante, en los relatos y perspectivas de las participantes está presente no sólo la dimensión simbólica y el ritual, sino — como en el caso de Tránsito-, una perspectiva que nos presenta a la muerte como algo bello a lo que no se le teme. Pero también está el afecto y el respeto por los muertos, como entidades que no desaparecen de nuestras vidas sino que nos acompañan, se presentan en sueños y en este sentido se merecen una digna sepultura como la imagen de Teresa atravesada por esta preocupación. 


\subsection{La importancia de las relaciones afectivas y sociales durante esta etapa de la vida: ejemplos a partir del collage}

En el tercer encuentro con el grupo, propongo el collage de forma libre para facilitar espontáneamente la emergencia de recuerdos, anhelos o preocupaciones presentes, ya sean conscientes o inconscientes. Cabe destacar que una de las ventajas de esta técnica es el uso de imágenes preexistentes, lo que para aquellos que no están familiarizados con las técnicas de representación constituye un atajo creativo.

Durante el proceso de selección y corte de imágenes todas se ven muy concentradas. Con excepción de Blanca no presentan dificultades motrices con el uso de las tijeras o el rasgado del papel. Entre las imágenes y verbalizaciones asociadas a ellas destaca el tema de la soledad, así por ejemplo María Isabel sobre su collage dice:

Le puse a la pareja porque me hubiese gustado seguir siempre así. Cuando vivía con mi pareja estaba así con mis hijos. Y bueno acá, esta imagen es cuando me separé y ya me tocó estar sola (el tono de voz de María Isabel cambia cuando toca el tema). Pero fui feliz con mis hijos a mi lado porque con ellos jugué, les enseñé muchas cosas, jugué a la pelota, les enseñé a bailar trompo, y cuando nos poníamos a ver la tele éramos felices de comer en la cama. Y acá puse esta imagen porque hasta el día de hoy nos gusta la navidad, porque es la única vez que nos reunimos todos. (Ver figura 5)

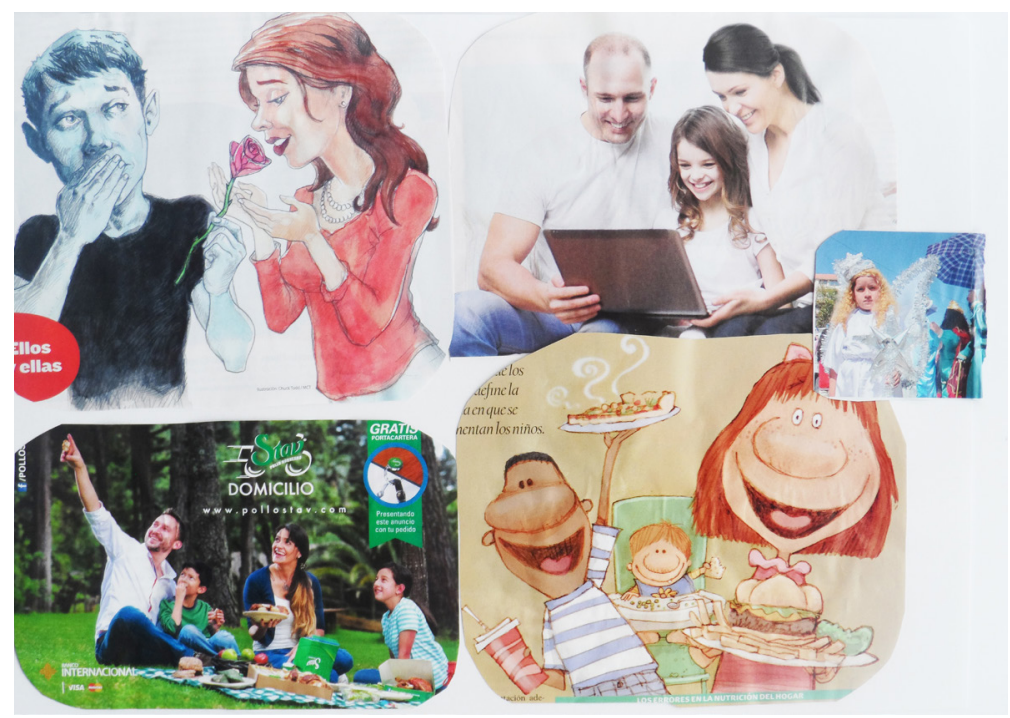

Figura 5

En el caso de Hilda y María Isabel, la experiencia de ser solteras y sentirse solas en la actualidad conlleva una serie de sentimientos que oscilan entre la tristeza profunda y la añoranza del afecto y el contacto físico de un compañero, hasta el sentimiento de orgullo y dignidad por no haber transigido frente a sus principios e integridad física y emocional. 
En ambos casos la decisión de apartarse tempranamente de parejas violentas les significó hacer frente a una trayectoria de doble y triple esfuerzo por la condición de madres solteras. En este sentido, son quienes más expresan el tema a través de sus creaciones y verbalizaciones, desde donde manifiestan principalmente la importancia de la compañía del otro, y el temor y el descontento de no contar con la ayuda necesaria para la gestión de ciertas cosas como cuando hay alguna limitación física o económica. En ambos casos los hijos se han transformado en los vínculos más importantes dentro de sus vidas.

Ana Rapoport (2011) quien investiga sobre este grupo etario, sostiene que el sentimiento y la experiencia de la soledad es algo que resalta en los procesos del envejecimiento. Para Ramos (2006) desde un enfoque de género, esto es así principalmente para aquellas mujeres mayores que han enviudado, se han separado o nunca tuvieron pareja o hijos. En este sentido y aunque las experiencias y nociones de soledad varían dentro del grupo, en general — aunque con excepción de Teresa-, se aprecia durante el proceso cierta aversión y temor frente al tema. Como es el caso de Hilda quien normalmente dibuja o pinta dos gallinas, dos árboles, etc., como una forma de conjurar la soledad.

Por otro lado y en oposición o complementación con el estar solas, destaca la importancia que le asignan a las relaciones ya sean estas con la familia más inmediata como esposos, hijos y nietos, o desde la experiencia socializadora — principalmente dentro del barrio - , con vecinos o compañeras de grupo.

Tránsito por ejemplo le pone de título a su collage «Alegría y felicidad» al preguntarle por qué este título, ella responde:

Porque estoy alegre, me siento bien, soy feliz porque se viene acá a estas cosas, se comparte con las compañeras. Me gusta cantar, bailar, me gusta que mis hijos sean jóvenes y me hagan reír. Y también porque mi esposo es bueno.



Figura 6 
En esta misma sesión Teresa incorpora al collage la imagen de un baile en un escenario y dice: «Puse esta porque me gusta bailar. Y esta otra porque paso bien, al menos con mis queridas compañeras». (Ver figura 6). Después añade, «Es importante la sociedad, estar en reunión». Sobre esto Ana - participante de 73 años-, dice: «es que cualquier chiste nos reímos, nos olvidamos de los problemas» y María Isabel añade: «Es que esas cosas son las que nos dan fuerza para salir adelante».

Esta valoración de las relaciones y su efecto inmediato en la percepción de la vida cotidiana de estas mujeres es abordado en mi trabajo de tesis desde el concepto de «capital social», en tanto - y como lo define Bourdieu - este conjunto de «recursos actuales o potenciales vinculados a la posesión de una red duradera de relaciones más o menos institucionalizadas de interconocimiento e interreconocimiento» (2001, p. 83-84) garantiza unos beneficios materiales y simbólicos que resultan no sólo útiles sino fundamentales para las participantes dentro de la comunidad.

\section{La imagen, el relato de vida y el cuerpo: destacados puntos de encuentro entre Arteterapia y Antropología Visual}

En el contexto de esta investigación, el cuerpo, la imagen y el relato de vida han sido entendidos no solo como nexos epistemológicos entre ambas disciplinas sino que han sido abordados como una continuidad expresiva y significativa, pues como señala Matoso:

El arte es una de las carnaduras identitarias del ser humano y en todo proceso creativo se ve implicada la imagen del cuerpo. No sólo como un posible rastreo biográfico del autor, sino la corporeidad que la obra de arte constituye en sí misma. $\mathrm{El}$ arte configura cuerpo. Carne e imagen (Matoso, 2011, p.11).

En este sentido los relatos de las informantes-participantes, tal y como plantea Arfuch (2010) el relato, han podido ser articulados desde las diferentes formas del lenguaje: oral, gráfico, pictórico, gestual, etc., y han constituido — como señala esta autora-, antes que una articulación secuencial de sucesos «históricos o ficcionales» (p. 87) una forma «de estructuración de la vida y por ende de la identidad» (p. 88).

Desde el arteterapia esta posibilidad narrativa que consiste en crear «puestas en escena imaginarias de uno mismo» (Klein, 2006, p.12) logra ser profundizada gracias a lo que Klein (2006) o Marxen (2011) denominan el «distanciamiento estético». Esto es, la posibilidad que tiene el sujeto mediante la creación de ficciones para pasar del discurso en primera persona (yo), a otro en tercera persona (él, ellos, etc.), lo que favorece una proyección del sí mismo sin la crudeza que implica una intervención directa.

Así mismo la imagen, de acuerdo con varios autores del arteterapia a sido entendida aquí como parte de un proceso que resulta tan o más importante que la imagen terminada, y en este sentido su lectura como captura de un solo significado no ha sido posible. Pues como señala Belting (2007) desde la antropología, una imagen «es más que el producto de la percepción», puesto que «se manifiesta como resultado de una simbolización personal o colectiva» (p. 14). 
Ardèvol \& Muntañola (2004) desde la antropología visual, coinciden en esto al señalar que las imágenes no sólo están en el mundo exterior listas para ser interpretadas, sino que estas además se crean y se construyen desde cada mirada particular, configurando nuestra realidad interior y nuestro universo simbólico.

En arteterapia encontramos aquellas imágenes materiales, como las que surgen de la pintura, el dibujo, la fotografía, etc., pero también aquellas imágenes inmateriales e internas que surgen por ejemplo desde la percepción táctil, o como ficciones imaginarias sin más cuerpo que el de las propias palabras. En este sentido, lo que se dice y lo que se calla, los ruidos y los silencios, tanto a nivel verbal como desde lo visual, han sido elementos claves para el análisis dentro del entramado de significación.

En cuanto al cuerpo, ya sea desde el trabajo con arte; desde la experiencia vital de ir envejeciendo; o desde mi propia relación con las informantes-participantes, constituye el medio fundamental para la ejecución, experimentación y comprensión de estos procesos. En este sentido, ha sido abordado - en primer lugar- desde los procesos implicados en el trabajo con arte. Esto incluye lo táctil, lo motor, lo visual y lo perceptual (como tocar, ver, oler, aplastar, recortar, etc.), información que es procesada según su carga afectiva o emocional y definida mediante los procesos cognitivos y simbólicos, en donde se ve involucrada por ejemplo la actividad verbal y la memoria (Lusebrink, 2004).

En segundo lugar, el cuerpo ha sido abordado desde la obra, desde la materialidad que esta encarna, y desde la materialidad que se transforma bajo la dirección de las creadoras con sus propios cuerpos. Y es que el cuerpo como dice Belting (2007) no solo es el que produce las imágenes sino que es el lugar de las imágenes.

En tercer lugar el cuerpo es abordado como una herramienta sensible de la metodología. En este sentido, desde la antropología y en resonancia con el arteterapia resulta oportuno el concepto de «cuerpo significante» como lo propone Citro (2009) para dar cuenta de un abordaje que toma en cuenta las relaciones que se tejen entre «las dimensiones perceptivas, motrices, afectivas y significantes en las experiencias intersubjetivas» (p. 12) entre agentes sociales e investigadores. Desde esta perspectiva el cuerpo es entendido además como agente trasformador de la praxis social y como un elemento etnográfico fundamental para la producción de conocimiento.

\section{Conclusiones}

Aunque el artículo sólo permite abordar pequeños fragmentos del proceso, la investigación completa arroja algunas ventajas de la integración de la imagen y los procesos creativos del arte en la investigación antropológica, como la posibilidad para acceder y apreciar aspectos sensoriales, motrices, afectivos, simbólicos, cognitivos y creativos de las participantes, los cuales hubiesen sido más difíciles de captar desde un acercamiento etnográfico tradicional.

De esto se desprende además la oportunidad que brinda el arte para llegar a los recovecos ocultos de la memoria, y de ahí, a la reconstrucción del pasado como elemento clave para comprender el presente del envejecimiento, entendiendo esta categoría antes que como una etapa dada, como un devenir inscrito en un contexto histórico, social, cultural y personal específico. 
Así mismo, imagen, cuerpo y relatos de vida, demuestran ser no solo puentes concretos entre antropología visual y arteterapia, sino excelentes formas comunicativas capaces de trascender — como dice Buxó citado por Marxen (2011) — «un modelo estrictamente lingüístico, de una semántica verdad, que asevera que las palabras significan y los mensajes comunican (...)» (p. 82).

Por otro lado - y en sintonía con lo que plantea Braidotti (2005) desde un feminismo de localización-, se destaca el potencial de la imagen y los procesos creativos del arte para generar espacios de conciencia política en tanto las participantesinformantes logran elaborar unas narrativas encarnadas y críticas de sí mismas, que incluyen unos procesos individuales pero también interactivos o relacionales, que permiten mediante el ejercicio de la reflexión, iluminar aspectos de la existencia y las relaciones de poder.

El arte se evidencia desde esta perspectiva, como un gatillador no sólo de recuerdos, sentimientos o anhelos, sino de reflexión y de búsqueda de nuevas posibilidades frente a lo que parece dado o normal, como son algunos de los patrones del machismo, o los estereotipos sobre el cuerpo de la vejez que se manifiestan dentro del proceso.

Finalmente y de acuerdo con la perspectiva de Fals Borda (2009) el propósito del método en la investigación social es producir conocimiento relevante para la práctica social y política, lo que implica la integración y el diálogo entre el punto de vista y la sabiduría popular y el conocimiento científico. De ahí que, lo esencial de la investigación participativa, como señala este autor no radica en la acción sino en «la naturaleza y el contenido del lenguaje empleado en la vivencia realizada, esto es, en la información, el diálogo y las modalidades que toma el contacto intersubjetivo del proceso creador» (p. 316). Siendo el arte y el lenguaje simbólico — según este autor-, efectivos mecanismos comunicativos capaces, no sólo de integrar el sentimiento y la estética en la comunicación, sino de producir investigación participativa, investigación sentipensante.

\section{Bibliografía}

Ardèvol. E. \& Muntañola, N. (2004). «Visualidad y Mirada. El análisis cultural de la imagen». En J, Adell, J, Fecé, B, Guarné, C, Propios, M, Selva, A, Solà. E, Ardèvol \& N, Muntañola (coord.)Representación y Cultura Audiovisual en la Sociedad Contemporánea, pp. 1546. Barcelona: UOC.

Ardèvol. E. (2009). Las técnicas de los sentidos: transformaciones de la práctica antropológica. Conferencia, IDES.7 de octubre 2009, Buenos Aires. https://eardevol.files.wordpress. com/2009/11/tecnicas_sentidos_ides.pdf

Arfuch, L. (2010). El espacio biográfico. Dilemas de la subjetividad contemporánea. Buenos Aires, Argentina: Fondo de Cultura Económica.

Aramburu, M., Tapada,T. \& Sabaté, I. (2011). La vivienda desde una perspectiva antropológica. XII Congreso de antropología lugares, tiempos, memorias. 2011, 6-9 septiembre, León. http://www.academia.edu/6127601/La_vivienda_desde_una_perspectiva_ antropol\%C3\%B3gica_introduction_to_workshop_with_M._Aramburu_and_T._Tapada

Braidotti,R.(2005).Metamorfosis.Haciaunateoríamaterialistadeldevenir.Madrid,España:AKAL. https://www.um.es/documents/378246/2964900/Normas+APA+Sexta+Edici\%C3\%B3n. pdf/27f8511d-95b6-4096-8d3e-f8492f61c6dc 
Bourdieu, P. (2001). El capital social. Apuntes provisionales. Letra internacional, 70 (4) pp. 83- 84. https://es.scribd.com/document/259726495/Bourdieu-Pierre-El-CapitalSocial-Apuntes-Provisionales

Belting, H. (2007). Antropología de la imagen. Buenos Aires: Katz.

Citro, S. (2009). Cuerpos Significantes: Travesías de una etnografía dialéctica. Buenos Aires: Biblios Culturalia.

Espinosa, A., Osorio, P. y Reyes, P. (2016): Interdisciplinary-action-research: Post-earthquake interventions with older people in Chile. Action Research 14 (3), pp. 276-294 https://doi. org/10.1177/1476750315607608

Fals Borda, O. (2009). Una sociología sentipensante para América Latina. Bogotá: Siglo del Hombre y CLACSO.

Hogan, S. \& Pink, S. (2010). Routes to Interiorities: Art Therapy and Knowing in Anthropology, Visual Anthropology, 23(2),p p. 158-174, DOI: Published online: 28 Jan. https://www.tandfonline.com/doi/abs/10.1080/08949460903475625

Klein, J. (2006). Arteterapia. Una introducción. España: Octaedro,

López, M. \& Martínez, N. (2006). Arteterapia, conocimiento interior a través de la expresión artística. Madrid: Tutor.

Lusebrink, V. (2004). Art therapy and the brain: An attempt to understand the underlying processes of art expression in therapy. Journal of the American Art Therapy Association. 21 (3), pp. 125-135. AATA, Inc. https://arttherapycourses.com.au/wp-content/ uploads/2016/01/Lusebrink-V.-B.-and-Alto-P.-2004.-ArtTherapy-and-the-Brain.pdf

Marxen, E. (2009). La etnografía desde el arte. Definiciones, bases teóricas y nuevos escenarios. Alteridades. 19 (37), pp. 7-22. Universidad Autónoma Metropolitana Unidad Iztapalapa. Distrito Federal, México. http://www.redalyc.org/pdf/747/74714813002.pdf

Marxen, E. (2011). Diálogos entre arte y terapia. Barcelona: Gedisa.

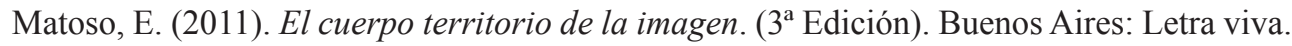

Paín, S. y Jarreau, G. (1995). Una psicoterapia por el arte. Argentina: Nueva Visión.

Ramos, M. (2006). Mujeres mayores: nuevos derechos para nuevas realidades. En V, Maqueira, (ed.), Mujeres, Globalización y Derechos Humanos, pp.191 - 244. Madrid: Cátedra,

Rapoport, A. (2011) «¿Envejecer solos o sólo envejecer? La exclusión social en la tercera edad». En L. Paniagua, M, De Virgilio, M, Otero, P, Boniolo (Coord.) Pobreza Urbana en América Latina y el Caribe, pp. 283-315. Argentina: CLACSO.

Schneider, A. \& C, Wright. (2006). El Desafío de la Práctica. En A, Schneider \& C, Wright (ed), Contemporary Art and Anthropology, pp.1-27. Oxford: Berg. (Traducción libre: X, Andrade).

Taussig, M. (2009). What Do Drawings Want? Culture,Theory and Critique, 50 (2), pp.263. 274. (Traducción libre: X, Andrade). https:/www.tandfonline.com/doi/ abs/10.1080/14735780903240299

Louis-Vicent, T. (1991). La muerte: una lectura cultural. España: Paidos. 